\title{
Rebranding Teacher Education for Diverse Settings in Zambia: A Development Aid from People to People Mkushi Teacher Education College Experience
}

\author{
Mubita Namuyamba $^{1^{*}}$, Stabile Namwai Ngambi ${ }^{2}$, Anolt L.H. Moonga ${ }^{3}$ \\ ${ }^{1}$ Adult Education, University of Zambia, Lusaka \\ ${ }^{2}$ Adult Education, University of Zambia Lusaka, Zambia \\ ${ }^{3}$ Adult Education, University of Zambia
}

\author{
*Corresponding Author: Mubita Namuyamba, Adult Education, University of Zambia, Lusaka, Zambia
}

\begin{abstract}
Teachers work in different locations some of which are hard-to -live in while others are modern with all the necessary amenities and services. Using the Development Aid from People to People Mkushi Teacher Education College (DAPP-MTEC) model in Mkushi, the study examined how graduates from this college were prepared for difficult work environments in the country. The objectives of the study were to: identify curriculum activities that students at DAPP-MTEC learn; ascertain challenges that graduates face in implementing the curriculum activities in their postings and to establish how these activities help graduates to adapt in their postings. The study employed a case study design on DAPP-MTEC which runs a unique program of training teachers for hard- to live environments and rural areas. The sample size was 50. The sample comprised of 10 lecturers, 10 graduates and 30 students of DAPP-MTEC in Mkushi District. The lecturers and graduates participated in in-depth interviews separately while the students responded to a questionnaire. The study found that curriculum activities that DAPP-MTEC students learn include Coadministration, bussing tours, functional groups, and rural community experience and entrepreneurship skills. The challenges teachers faced included language barrier, some activities were time consuming, inadequate materials, adaptation problems, long distances between social amenities and inadequate infrastructure. The findings on how graduates can adapt were improving infrastructure, stakeholder involvement, conducting research, community sensitization and orientation of the graduates. The recommendations were that curriculum specialists should include areas that harness flexibility and selfreliance for adaptation and that government should put more effort in formulating policies that will provide a conducive environment in difficult to live areas supported by provision of adequate teaching and learning resources.
\end{abstract}

Keywords: curriculum, teacher education, difficult, rural area, hard-to- live

\section{INTRODUCTION}

The world over teacher education serves as a mirror to the needs of the communities in which they are and society at large. As a result there is a likely hood of teacher education curricular to vary from one place to another. This is because the community served by the graduates demand certain key values of society to be included in the handling of their children (learners) at all levels. In Zambia it can generally be stated that the existing teacher education curriculum is common in all the institutions providing teacher education as it is aimed at training a generic teacher that can serve in all parts of the country regardless of terrain and social variations. In any case, until the late 1990s teacher education was provided mainly by the government and Christian missionaries (MOE, 2013).

In 1996, the Ministry of education liberalised the provision of teacher education by allowing many players such as individuals, associations and other players of society to participate in teacher education provision. This was in order to meet the large demand for teachers that the country faced at all levels (MOE, 1996).

The Development Aid from People to People (DAPP), a humanitarian association originating from Scandinavian countries after working with disadvantaged children in the children's homes in Chibombo, Solwezi and Mkushi identified difficulties of retaining teachers for rural areas (DAPP, 
2014). Many teachers from conversional colleges were more inclined to working in urban areas or in local towns where amenities usually found in urban areas were common. This prompted DAPP to start a teacher education programme that was tailored to address the hardships that communities in rural areas face. DAPP (2014) states that in 2009 the Development Aid from People to People Mkushi Teacher Education College (DAPP-MTEC) was established with a deliberate bias to training teachers that would withstand the hardships of rural areas in Zambia. Coincidentally, DAPP-MTEC is located at the foot of the western side of the Muchinga Escarpment which makes the environment very difficult to leave in.

Although the Ministry of Education has increased opportunities for the training of teachers, the placement of teachers is still uneven according to the urban and rural divide. Urban areas with many modern amenities are better staffed than rural areas. This equation would be endless if there are no initiatives and innovations to address it like the DAPP-MTEC. This college was designed to follow the general teacher educational curriculum of the country with special attention to equipping its graduates with knowledge and skills that can make the graduates survive the hardships in rural areas. The study sought to examine the curriculum that has been used to 'rebrand' the Zambian teacher Education programme.

\section{OVERVIEW OF LITERATURE}

In Zambia, the Ministry of higher education ushered in the content of the revised curriculum by making it flexible and responsive to learner and societal needs, institutions of learning, teachers and teacher-educators are encouraged at all levels of the education system to localize some aspects of the school curriculum. The localization of the school curriculum will allow colleges and schools to adapt aspects of the curriculum to match local needs and circumstances. In this way, the curriculum will provide some compensation for the indigenous knowledge, values and practical skills that students and learners would have acquired in their home environment if they had not been attending school. The co-curricular activities that students are expected to be involved in as part of the school curriculum include: Clubs and Associations, Sports, Preventive Maintenance and Production Units (MoE, 2013). Curricular activities are organized activities, which are part of the formalized teaching schedule. They are a major channel for the development of life skills and formation of positive attitudes and behavior patterns. With the foregoing, learning institutions should deliberately include in their program co- curricular activities for all students and learners. They can also extend the services to the school's immediate neighborhood.

A study by Katitia (2015) in Kenya revealed that the teacher education curriculum consisted of five core subjects that are compulsory for all students - English, Kiswahili, professional studies, physical education and information communication and technology (ICT). The study did not highlight other curriculum activities that teachers are exposed to which set the stage for the current investigation.

In the views of Ocansey \& Davies (2016) the areas covered in the Ghanaian 2005 curriculum were found to be Content Course, Educational and Professional Studies Courses, Methodology Courses, Practical Activity Courses and General Studies Courses. The duo went on to say that Content courses include English, mathematics, Ghanaian language and culture, integrated science environmental and social studies, prevocational skills, moral studies, technical skills and French. The authors further alluded to the fact that technical skills and French are options. In the opinion of Ocansey \& Davies (2016) practical activities such as music and dance are also intended to prepare the trainee for effective handling of the subjects at basic level. The above sentiments were presented at a stakeholder's conference and the methods of investigation that were used to arrive at these findings were not stated therefore, the current study set out to investigate the curriculum activities in the quest to address difficulties in hard to live places.

The other sentiments presented by Guenther \& Weible (1983) are that while a totally unique preparation program is not possible for most institutions there is a growing concern for the need of a more adequate preparation for rural teachers throughout the country, a justification enough to identify curriculum activities and how the teachers address them in the Zambian setting.

Since majority of the people are extremely poor, one of the escape routes that have been advanced in the literature is adequate investment in human capital (Mulkeen, 2005). While resources for human 
capital investment are inadequate in the region, inequality in the distribution of these resources poses an additional challenge. More often, there are inequalities along gender lines and between urban and rural divides with many governments focusing more on urban areas and less on rural areas.

A study conducted by Guenther and Weible (1983) on preparing teachers in rural schools in the United States of America, revealed that the problems facing teachers in the nation's rural schools, for the most part, had been neglected. Politicians and professional educators have focused their attention toward urban education, leaving many to assume that all is well in the schools of rural America. The seeming urgency of such 'urban' problems as busing, low achievement test scores, school violence and vandalism, and teacher turnover have repeatedly captured political and professional audiences leaving the dilemmas facing rural educators all but forgotten (Tyler, 1949).

Guenther and Weible (1983) indicated that teachers who practice in rural schools, either by choice or accident, face challenges to their potential effectiveness not generalizable to all teaching situations, and that specific programs are needed to increase the competencies necessary for teaching in these schools. Poor quality of schooling is evident in many ways in the public school system, especially in the rural areas; and is exhibited in the rate of absenteeism and the inability of children (primary school outputs) to read and write effectively (Adedeji \& Olaniyan, 2011). In Zambia particularly at DAPP Mkushi College of Education (DAPP-MTEC) it was not known how poor schooling as a result of rural settings contributed in bottle-necking political, social and economic transformations, hence the current study.

Adedeji and Olaniyan (2011) added that rural schools face difficulties recruiting and retaining a qualified teacher workforce. Potential contributing factors include social and collegial isolation, low salaries, multiple grade or subject teaching assignments, and lack of familiarity with rural schools and communities. Together, these challenges can discourage teachers from accepting rural positions or cause them to leave rural settings after teaching there for only a short time. While the shortage of qualified teachers in rural areas is not a new phenomenon, the passage of the No Child Left Behind Act of 2001 brought an added sense of urgency.

In Dwamena (2011)'s study, Ghanaian graduates from many schools were found not prepared for college and citizenship, because standardized tests were shaped by outdated colonial notions of academic rigor and by political and financial considerations. The education system has been characterized by lack of adequate teaching aids, absence of effective syllabi, inadequate textbooks, depleted school infrastructure, and low budget outlay from the government. In order to excel in learning tasks and the capacity to experience pride in accomplishment the curriculum ought to be a catalyst that will allow students to acquire intrinsic motivation in their quest through school and beyond. The school curriculum should provide a broad and balanced learning experience and a pupilcentered school-based curriculum that is diversified, flexible, and coherent across levels to foster lifelong learning. The outcome of the above study has shown numerous challenges that come with the graduates from many colleges into schools as a result of not having enough preparation. However, Dwamena (2011)'s study differed from the current study in that it focused on the challenges faced by graduates from many colleges into schools while the current study explored curriculum activities students learn in DAPP Mkushi College of Teacher Education ( DAPP-MTEC).

In line with this initiative of believing in the right to education, Development Aid from People to People (DAPP) signed a Memorandum of Understanding with the Zambian Ministry of Education in order to establish 8 Teacher Training Colleges. DAPP-MTEC was one of the first Zambian teacher training colleges established in 2012. The college is training teachers for rural primary schools where there is a growing demand for qualified teachers. This College of Education has the purpose of training and providing multiple skills to teachers who will be ready to render their service to schools in the remote areas of Zambia, where there is most need of education. The unique training programme provides an all-round education to student teachers preparing them to become passionate teachers with the will, heart and skills to work in rural areas.

Although many studies world over have clearly shown how important it is to implement co-curricular activities in colleges and schools in the education system, scanty documentation of literature was found by researchers on co-curricular activities that students learn in colleges of education. This study thus investigated the curriculum activities at DAPP-MTEC. 
ILO (2016:4) found that in Uganda, "The curriculum needs overhauling in to one that is more relevant to our society. Today it is more exam oriented, so children are only taught to pass exams instead of learning to become people of character and integrity, identifying talents to do things they love in future. We are producing people who will do jobs that they are not passionate about, which erode performance instead of adding value. It would be great if the curriculum were revised to nurture children's talents and interest early on, because our current curriculum tends to encourage dependency on rote learning and memorization instead of nurturing children's creativity, critical thinking skills, and imagination, (qualities) which spark innovation.

\section{AIM}

The purpose of this study was to investigate the curriculum activities that students learn at DAPPMTEC in Mkushi District so as to help rebrand teacher curriculum and make teachers adapt in hard to live areas. The objectives of the study were to: identify the curriculum activities that students at DAPP-MTEC learn, to explore challenges faced by graduates in implementing the curriculum activities learnt at DAPP teachers' education college in their posting; and to establish how these curriculum activities help graduates to adapt to their postings.

\section{Methodology}

The study utilised a case study design in order to have an in-depth understanding of the co-curricular activities that students learn at DAPP Mkushi Teacher Education College. The population comprised of DAPP Mkushi Teachear Education College lecturers, graduates and students. The sample comprised of 10 lecturers, 10 graduates and 30 students of DAPP Mkushi Teacher Education College. The sample size was 50. The 10 lecturers and 10 graduates participated in separate in-depth interviews while the 30 student teachers at DAPP Mkushi Teacher Education College responded to questionnaire. The lectures were purposely chosen as they had the knowledge that was beneficial to the study. The graduates were picked using snowball sampling as one led to the other. The students were sampled using a simple random sampling procedure. Data from the interview guides and questionnaires was analyzed thematically and presented objective by objective with the help of pie charts generated in Excel.

\section{RESULTS AND DisCUSSIONS}

\subsection{Extra curriculum activities that students at DAPP Mkushi teacher education college learn}

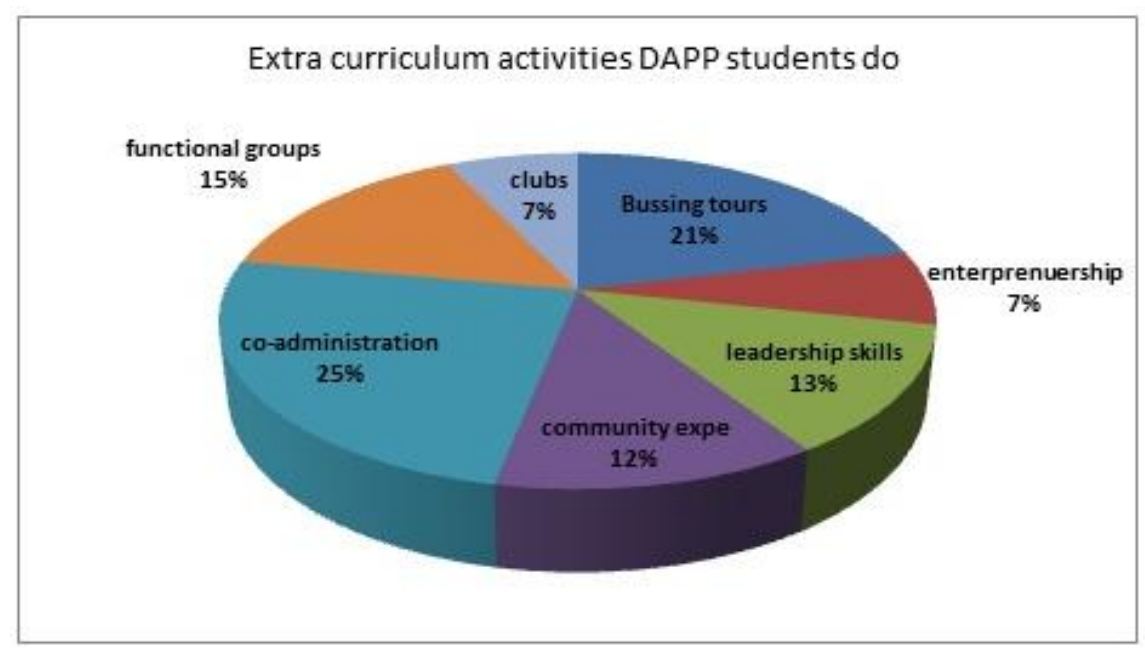

Figure1: Distribution of respondents' views on the extra curriculum activities that they learn

Figure 1 above shows that 25\% respondents indicated that they learn co-administration skills of how to co-govern Mkushi DAPP Teacher Education College with the institution's management. $21 \%$ of the respondents alluded to education tours commonly known as bussing the continent as the activity they learn. $15 \%$ of the respondents submitted that functional groups were the activity they learn at the college. $13 \%$ of the respondents outlined leadership skills as the activity they learn. Community experience was accounted for by $12 \%$ of respondents as their learning activity. The least represented learning activity was entrepreneurship skills by $7 \%$ of the respondents. 
Rebranding Teacher Education for Diverse Settings in Zambia: A Development Aid from People to People Mkushi Teacher Education College Experience

Responses from interviews with DAPP Mkushi Teacher Education College graduates on extra curriculum activities they learnt at DAPP Mkushi Teacher Education College

a. Bussing or taking educational tours within the country and in other countries: The graduates pointed at bussing or educational tours within the country to sister colleges and outside the country as components of the activities that they learnt in their curriculum. One female graduate had this to say:

Bussing helped me to understand the education system in other countries,

and that enriched my knowledge on how to solve different problems that

I encounter in my work environment.

She also said that 'we learnt how to adapt to various environments as we sometimes traveled to areas that did not have social amenities to the extent of sleeping in tents in the coldest months of the year.'

b. Rural Community Experience: Rural community experience was also a common finding from the graduates of DAPP College. The graduates indicated that community attachment was an activity that they carry out as a part of the curriculum. One graduate happily point out that:

We were made to have firsthand experience working in rural areas, fighting

Poverty and illiteracy together with the poor in the community. This enabled

me learn how to adapt to difficult environments by actually experiencing the process.

Another graduate had this to say:

I learnt life skills on how to adapt in hard to survive environments by doing activities that the people in the rural community were doing. These activities included farming and bricklaying. I was also taught how to maintain the environment clean and neat by doing house repairs myself.

c. Leadership Skills: A number of graduates stated that Leadership skills were part of the activities that they had acquired from the college. One graduate had this to say:

We were part and parcel of the school management decision making process

which I do not think other colleges of education entertain. We were always

made to sit in weekly activity evaluation meetings with the institutional

management and even in the monthly management and budgeting meetings.

We also had a fair hearing on all the day today running of the institution.

d. Entrepreneurship Skills: Graduates from Mkushi College further indicated that they learnt entrepreneurship skills. One of the graduates explained that:

Entrepreneurship skills are a crucial part of the curriculum as I still

Implement what I learnt a few years ago in my day to day activities

and earn some money from carpentry work at to my workshop.

e. Sports and Clubs: The participants in the interview also alluded to sports and clubs as activities they leant at the college. A male graduate further shed more light that:

It was compulsory for each student to belong to at least one club and

to be involved in sports We were always reminded of the need for us

to be physically and mentally healthy. We received education of the

head, hand and the heart.

\subsubsection{Discussion}

These findings are in tandem with the submissions of Ocansey \& Davies (2016) who outlined that the areas covered in the Ghanaian 2005 curriculum were Content Course, Educational and Professional 
Studies Courses, Methodology Courses, Practical Activity Courses and General Studies Courses. The duo went on to say that Content courses include English, mathematics, Ghanaian language and culture, integrated science environmental and social studies, prevocational skills, moral studies, technical skills and French. However the authors did not specify the extra curriculum activities of the Ghanaian curriculum at the time thus hence the purpose of the current study.

The findings that DAPP Mkushi College offers bussing or educational trips, rural community experience, leadership skills, entrepreneurship skills, functional groups and sports as curriculum activities are in agreement with those in a paper based on country case studies done in conjunction with the World Bank in Lesotho, Malawi, Mozambique, Uganda and Tanzania by Mulkeen (2005:1) who opinionated that:

$$
\begin{aligned}
& \text { “...parents in rural areas often have a lover level of education, and may } \\
& \text { attach a lower value to schooling. The perceived lack of relevance of } \\
& \text { schooling may be enhanced by a rigid curriculum, often designed } \\
& \text { for a context (and sometimes culture) removed from that in rural } \\
& \text { areas. Schools rarely adapt the curriculum to make use of local } \\
& \text { examples, or link the curriculum to local needs.” }
\end{aligned}
$$

On the one hand the current findings sharply contrast those from Katitia (2015) who put great emphasis on a curriculum that would make teachers understand and know the subjects that they teach including the knowledge of central facts, concepts, theories and even procedures within a given field, knowledge of explanatory frameworks that organize and connect ideas, and knowledge of the rules of evidence and proof. The current study differs from Katitia's in the sense that it was a qualitative case study that brought views of the stake holders different from Katitia's paper.

The curriculum activities that students at DAPP Mkushi College learn include Co-administration, bussing tours, functional groups, and rural community experience and entrepreneurship skills.

\subsection{To ascertain challenges that graduates face when implementing activities that they learnt}

\subsubsection{Findings from the questionnaire administered on students}

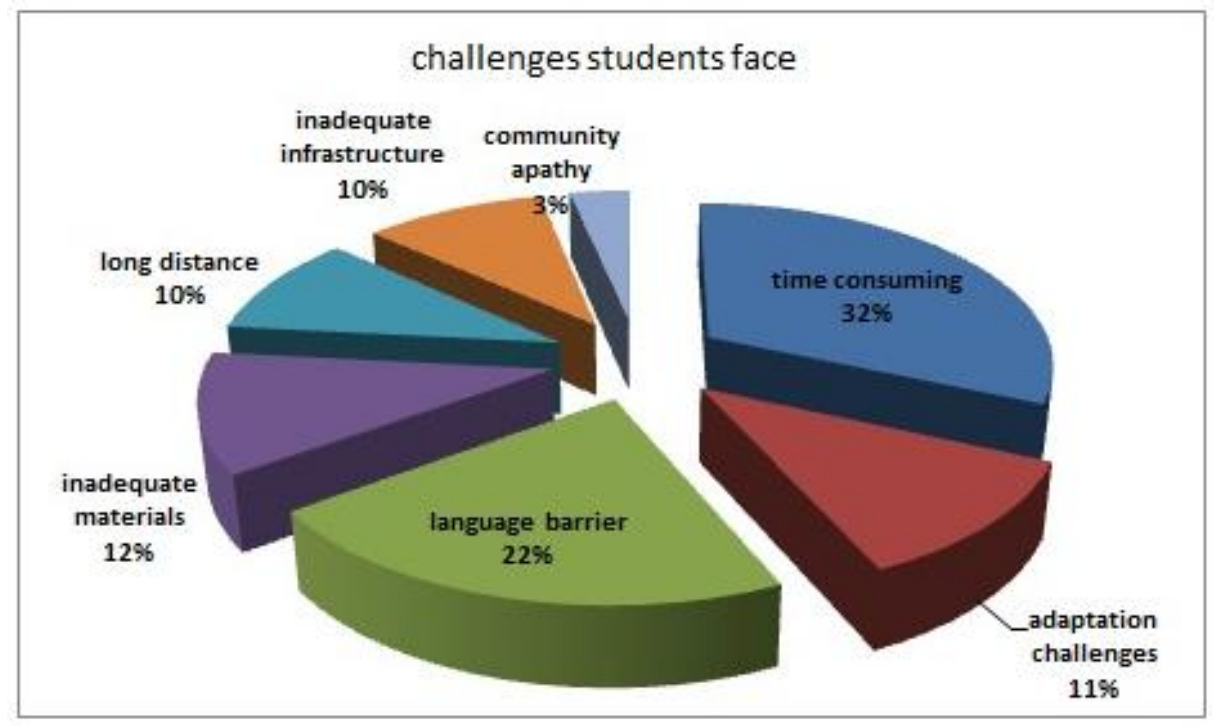

Figure2: Distribution of respondents' views on the challenges that students face at the College

Pie chart 2 above shows the majority of students represented by $32 \%$, highlighted that the activities are time consuming as a challenge they encounter when implementing what they learn at the college. $22 \%$ of the respondents pointed at language barrier as the challenge students face. $12 \%$ of the respondents pointed out that inadequate materials were some of the challenges students face at the College. $11 \%$ of the respondents intimated that students had challenges with adaptation. $10 \%$ of the respondents intimated that long distances between social amenities was one of the challenges 
encountered. Another $10 \%$ of respondents specified that inadequate infrastructure contributed to the challenges students experienced. 3\% of the respondents submitted that apathy from community posed as a challenge to the would be teachers.

\subsubsection{Discussion}

The study has established that the challenges that teachers from DAPP Mkushi College face when implementing what they had learnt are varied. These include that it is time consuming, language barrier, inadequate materials, adaptation problems, long distances between social amenities and inadequate infrastructure.

These findings disconfirm those of Guenther \& Weible, 1983 who found that the problems faced by teachers in rural schools in America indicated that rural schools were characterized by limited faculty and administration (Guenther \& Weible, 1983).

The DAPP Mkushi college model findings has contrasted the priority area that was forwarded by the submission from a study by Adedeji and Olaniyan (2011) in Nigeria, that the challenges faced by teachers in the adaptation to their postings were found to be low pay. (Adedeji \& Olaniyan, 2011:56) were of the view that, "The common axiom among teachers is that Teachers take home pay cannot take them home." The findings from the current study revealed a different array of challenges that require a different focus in alleviating the flaws of the teacher Education system in Zambia for purposes of rebranding and effectiveness.

The study has established that the challenges teachers from DAPP Mkushi College face when implementing what they had learnt are varied. These include that it is time consuming, language barrier, inadequate materials, adaptation problems, long distances between social amenities and inadequate infrastructure. Such situations negatively affected the adaptation and survival of teachers in hard to live in environments.

\subsection{To establish how these activities help graduates to adapt in their postings.}

This segment presents the findings from lecturers, graduates and DAPP Mkushi Teacher Education College on how to help graduates adapt in their postings.

5.3.1 Responses from the questionnaire administered on students on how to address the challenges faced at DAPP Mkushi College

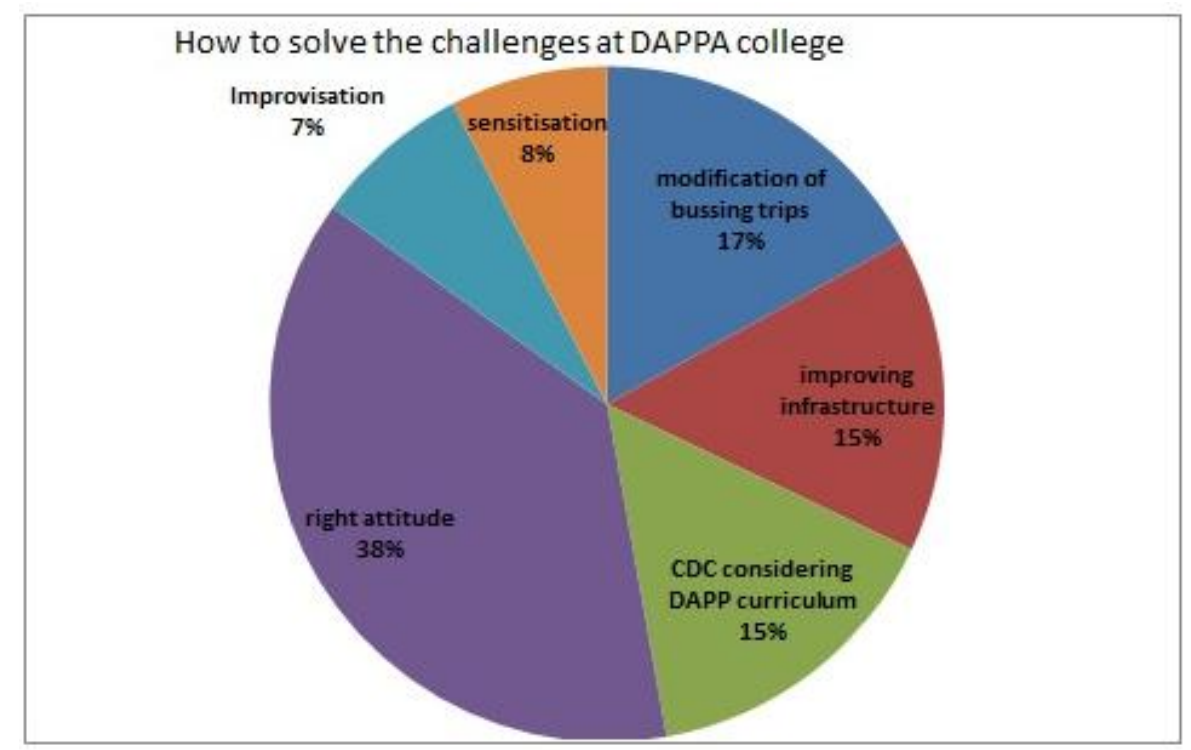

Figure3: Distribution of respondents' views on how to address the challenges that students face at DAPP Mkushi Teacher Education College

Pie chart 3 above shows that majority of students indicated by $38 \%$ mentioned right attitude or adaptation towards ones work and environment as one the way of addressing the challenges faced by students at Mkushi DAPP College. 17\% of the students suggested that modification of bussing or educational trips by reducing on the duration of tours and allowing lecturers to continue teaching the 
main curriculum content alongside the trips would help solve some of the challenges at the college. $15 \%$ of the respondents advocated for the Curriculum Development Centre (CDC) to consider the full range of activities of the college in their programming. Another $15 \%$ of respondents advised improving infrastructure. $8 \%$ of the respondents alluded to community sensitization while the lowest was Improvisation represented by $7 \%$ of the respondents.

5.3.2 Responses from interviews with DAPP Mkushi Teacher Education College Lecturers on how to address the challenges in postings

The responses from the lecturers to the question on how to address the challenges in areas of postings included the following.

Improving infrastructure: One of the respondents alluded to improvement of infrastructure to provide a suitable environment for the students to learn from. One lecturer categorically suggested that:

There is need to build state of the art library to help the students have a broader perspective of knowledge.

Good orientation for Adaptability: A lecturer who was involved in an interview emphasized the fact that students should be given proper orientation before they begin their studies. The lecturer went on to say that:

There is need for adequate orientation of learners at the very beginning of

the program in readiness for the dynamic curriculum and the inevitable

hard to live in environment that the graduate would be posted to work in.

The participants in the interview showed how a good orientation would prepare the learners have an appropriate mind set and right attitude irrespective of the future circumstances and challenges.

Stakeholder Involvement: Lecturers suggested that stakeholder involvement of community, governmental and non-governmental organizations was at the heart of a robust Teacher Education system. One respondent proposed that:

Public private partnerships have not been fully utilized hence the need

to foster these partnerships for purposes of improving teacher education

and especially for preparation of learners of would be teachers in hard

to live in areas or rural areas.

Research: A lecturer during the interview underscored the need to engage in research in the quest to address the challenges faced by Mkushi graduates in their areas of postings. He accentuated that:

The advantage of students and lecturers' commitment in research

so that they share and generate knowledge on how to address

the challenges in hard to live environments.

\subsubsection{Discussion}

From the aforementioned findings, the study established that the challenges faced by graduates from the college could be addressed by improving infrastructure, stakeholder involvement, conducting research, community sensitization and orientation of the graduates so that they may have the right attitude of adaptation and survival prior to their commencement of work.

The above solutions to the challenges faced by teachers in hard to survive areas are in line with the recommendations intimated by Guenther \& Weible (1983:59), the duo underscored, “... the need for preservice/in-service programs for rural teachers and suggest program components that may improve the teacher competencies."

In relation to the findings from the study, curriculum activities that could help graduates adapt in their postings include revelations about improving infrastructure, stakeholder involvement, conducting research, community sensitization and orientation of the graduates. From the foregoing study findings also indicate that teachers ought to be adequately prepared in all manner of service for them to effect a 
change in the community they find themselves in as demonstrated from the model of DAPP Teacher Education College which endeavors to prepare teachers for delivery of services in a way that other colleges of education can benefit from with appropriate modification of some factors to rebrand teacher education for a better community.

\section{CONCLuSion}

Based on the literature review, findings from respondents and the discussions, the study has established that the curriculum activities that students at DAPP Mkushi College learn include Coadministration, bussing tours, functional groups, and rural community experience and entrepreneurship skills.

The study has established that the challenges that teachers from DAPP Mkushi College face when implementing what they had learnt are varied. These include that it is time consuming, language barrier, inadequate materials, adaptation problems, long distances between social amenities and inadequate infrastructure. Such situations negatively affected the adaptation and survival of teachers in hard to live in environments.

In relation to the findings from the study, curriculum activities that could help graduates adapt in their postings include revelations about improving infrastructure, stakeholder involvement, conducting research, community sensitization and orientation of the graduates. From the foregoing study findings also indicate that teachers ought to be adequately prepared in all manner of service for them to effect a change in the community they find themselves in as demonstrated from the model of DAPP Teacher Education College which endeavors to prepare teachers for delivery of services in a way that other colleges of education can benefit from with appropriate modification of some factors to rebrand teacher education for a better community.

\section{RECOMMENDATIONS}

The recommendations were that curriculum specialists should include areas that harness flexibility and self-reliance for adaptation and that government should put more effort in formulating policies that will provide a conducive environment in difficult to live areas supported by provision of adequate teaching and learning resources.

\section{REFERENCES}

[1] Adedeji, S, O. \& Olaniyan, O. (2011). 'Challenges Facing Rural Education in Africa' In Fundamentals of Teacher Education Development: Improving the Conditions of Teaching in Rural Schools across African Countries. Addis Ababa: UNESCO

[2] DAPP (2014). Development Aid from People to People: Mkushi College of Education Year Report January to December 2014. DAPP

[3] Guenther, J \& Weible, T. (1983) 'Preparing Teachers for Rural Schools' Rural Education. I:2:1983

[4] Katitia, D. M.O. (2015). 'Teacher Education program for the $21^{\text {st }}$ Centuary. Which way forward for Kenya?' Journal of Education and practice. 6:24 ISSN 2222-1735

[5] Ministry of Education (2013). Education Curriculum Framework. Lusaka: Curriculum Development Centre.

[6] Mulkeen, A. (2005). Teachers for Rural Schools: A Challenge for Africa. World Bank.

[7] Ocansey, F. \& Davis, K. E. (2016). Stakeholders' Meeting Held at the NCTE Conference Room, 31st March. 'The Diploma in Basic Education Curriculum for the Colleges of Education. 'Cape Coast: University of Cape Coast.

[8] Tyler, R (1949). Basic Principles of Curriculum and Instruction. United States of America: University of Chikago.

\section{AUTHORS' BIOGRAPHY}

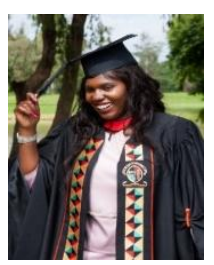

MubitaNamuyamba is a Part Time Lecturer and researcher in the Department of Adult Education and Extension Studies at the University of Zambia. She is also a Clinical Officer at UNZA Health Services. She also provides capacity building consultancy in various organizations 
Rebranding Teacher Education for Diverse Settings in Zambia: A Development Aid from People to People Mkushi Teacher Education College Experience

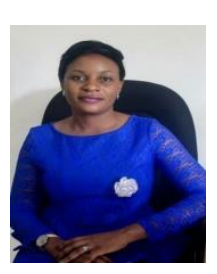

Stabile NamwaiNgambi is a lecturer in the Department of Adult Education and Extension Studies at the University of Zambia.

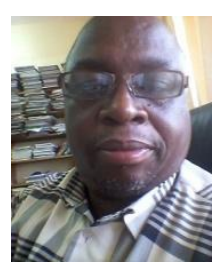

Anolt L.H. Moonga is a lecturer and Head of the Department of Adult Education and Extension Studies at the University of Zambia.

Citation: Mubita Namuyamba, Stabile Namwai Ngambi, Anolt L.H. Moonga. "Rebranding Teacher Education for Diverse Settings in Zambia: A Development Aid from People to People Mkushi Teacher Education College Experience". International Journal of Humanities Social Sciences and Education (IJHSSE), vol 5, no. 2, 2018, pp. 98-107 doi: http://dx.doi.org/10.20431/2349-0381.0502011.

Copyright: (C) 2018 Authors. This is an open-access article distributed under the terms of the Creative Commons Attribution License, which permits unrestricted use, distribution, and reproduction in any medium, provided the original author and source are credited. 